23

\title{
Упрочнение зеркальной поверхности за счет нанесения углеродной наноструктуры
}

\author{
(C) В.И. Батшев ${ }^{1,2}$, А.Б. Козлов ${ }^{1,3}$, А.С. Мачихин ${ }^{1}$, \\ М.О. Макеев ${ }^{2}$, А.С. Осипков ${ }^{2}$, М.Ф. Булатов ${ }^{1}$, \\ И.Ю. Кинжагулов ${ }^{4}$, К.А. Степанова ${ }^{4}$
}

${ }^{1}$ Научно-технологический центр уникального приборостроения РАН, 117342 Москва, Россия

${ }^{2}$ МГТУ им. Н.Э. Баумана,

105005 Москва, Россия

${ }^{3}$ АО «НИИ „Полюс“ им. М.Ф. Стельмаха»,

117342 Москва, Россия

${ }^{4}$ Университет ИТМО,

197101 Санкт-Петербург, Россия

e-mail: batshev@bmstu.ru

Поступила в редакцию 03.06.2019 г.

В окончательной редакции 03.06.2019 г.

Принята к публикации 11.06.2019 г.

\begin{abstract}
Рассмотрена задача упрочнения зеркальных поверхностей астрономической оптики космического базирования и защиты ее от внешних факторов. Для решения этой задачи рассмотрена возможность нанесения на них углеродных алмазоподобных покрытий. На примере зеркал с покрытием из $\mathrm{Al}$ и Сu экспериментально показано, что нанесение на них углеродного слоя толщиной $30 \mathrm{~nm}$ методом импульсного лазерного осаждения приводит к увеличению твердости поверхности на 25\% и 100\% соответственно. Установлено, что упрочняющее покрытие не влияет на погрешности формы зеркал и шероховатость их поверхности. При этом существенно снижается коэффициент отражения в видимом диапазоне $(400-780 \mathrm{~nm})$, тогда как в инфракрасном $(>780 \mathrm{~nm})$ коэффициент отражения снижается не более, чем на $5 \%$.
\end{abstract}

Ключевые слова: зеркало, алмазоподобное покрытие, упрочнение, углеродная наноструктура.

DOI: $10.21883 /$ OS.2019.10.48361.174-19

\section{Введение}

Почти всю информации об астрономических объектах в настоящее время получают с помощью телескопов наземного и космического базирования, работающих в различных спектральных областях электромагнитного излучения: от рентгеновского до радио [1]. Основными недостатками наземных телескопов является атмосферное поглощение, существенно ограничивающее спектральный состав и количество регистрируемого излучения, а также турбулентность атмосферы, ограничивающая качество изображения. Поэтому активно эксплуатируются и создаются космические телескопы [1-3]. При этом выведение телескопа на орбиту сопряжено с множеством трудностей, одной из которых является воздействие космических факторов (в первую очередь - ионизирующего излучения) на отражающие поверхности зеркал. В наземных телескопах проблема ухудшения качества зеркал под воздействием внешних факторов решается при периодическом техническом обслуживании телескопа [1]. В телескопах космического базирования это невозможно, поэтому актуальной является задача упрочнения отражающих поверхностей зеркал космических телескопов.
В настоящей работе исследована возможность защиты отражающих поверхностей зеркал, работающих в видимом и ближнем инфракрасном диапазонах, путем нанесения на их поверхность углеродных алмазоподобных покрытий (diamond like coatings, $D L C$ ) методом импульсного лазерного осаждения. Данный класс наноструктурных покрытий, состоящих из атомов углерода как с алмазными $\left(s p_{3}\right)$, так и с графитоподобными $\left(s p_{2}\right)$ связями, характеризуется высокими прочностными и износостойкими свойствами, в частности, высокой твердостью от 5000 до $10000 \mathrm{Hv}$, низким коэффициентом трения от 0.15 до 0.08 ; высокой износоустойчивостью и химической инертностью. Это обусловливает их широкое применение в различных областях науки и техники, в том числе в оптическом приборостроении $[4,5]$. В то же время коэффициент преломления алмазоподобных покрытий лежит в диапазоне от 1.55 до 2.20 [6] в зависимости от технологии изготовления, а коэффициент поглощения близок к нулю в широком диапазоне длин волн $[7,8]$. Такие уникальные свойства позволяют улучшить показатели надежности (долговечность и безотказность) оптических изделий при сохранении значений ключевых показателей качества на высоком уровне $[5,7]$. 


\section{Установка для нанесения упрочняющих алмазоподобных покрытий}

Нанесение упрочняющих алмазоподобных покрытий осуществлялось методом импульсного лазерного осаждения на базе нанотехнологического комплекса Нанофаб-100 (NT-MDT) [9]. Нанофаб-100 является модульной технологической платформой для формирования нанотехнологических комплексов с кластерной компоновкой.

Отличительная особенность импульсного лазерного осаждения заключается в формировании слоя в режиме с остановкой роста, приводящим к завершению всех поверхностных атомных процессов до начала обработки последующим импульсом [10], что позволяет добиваться стехиометричного переноса многокомпонентного материала. Процесс нанесения заключается в воздействии лазерного излучения на материал мишени, поглощении излучения, разлете продуктов воздействия и осаждении их на подложку. При этом взаимодействие лазерного излучения с плазмой продуктов абляции приводит к повышению степени ионизации и энергии частиц.

В качестве источника излучения использовался

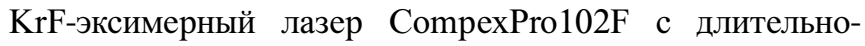
стью импульса $30 \mathrm{~ns}$ и длиной волны $248 \mathrm{~nm}$. Ocaждение пленок осуществлялось без нагрева подложек при температуре нагревателя над подложкой $25^{\circ} \mathrm{C}$ и плотности энергии лазерного излучения до $1.5 \mathrm{~J} / \mathrm{cm}^{2}$. Для обеспечения однородности слоев использовалось вращение мишени и подложки, а также движение луча по поверхности углеродной мишени. Материал мишени - пиролитический графит. Схема импульсного лазерного осаждения показана на рис. 1.

\section{Экспериментальные исследования}

Для определения эффективности описанного метода были изготовлены две серии образцов зеркал диаметром $20 \mathrm{~mm}$. В качестве подложки использовались плоскопараллельные пластины из К8 толщиной $5 \mathrm{~mm}$. Методом магнетронного напыления на образцы первой серии был нанесен слой $\mathrm{Cu}$ толщиной $500 \mathrm{~nm}$, a методом ионного распыления на образцы второй серии - слой $\mathrm{Al}$ толщиной $300 \mathrm{~nm}$. Далее наносилось алмазоподобное покрытие согласно приведенной на рис. 1 схеме. Основные параметры процесса приведен в табл. 1 .

Толщины $\quad D L C$-покрытий определялись методом ИК спектроскопической эллипсометрии на приборе IR-VASE в диапазоне длин волн от 300 до $5000 \mathrm{~cm}^{-1}$ при спектральном разрешении $4 \mathrm{~cm}^{-1}$ и углах падения излучения на образец $50^{\circ}, 60^{\circ}$ и $70^{\circ}$. Построение эллипсометрических моделей выполнялось в программной среде WVASE32 [11], с помощью

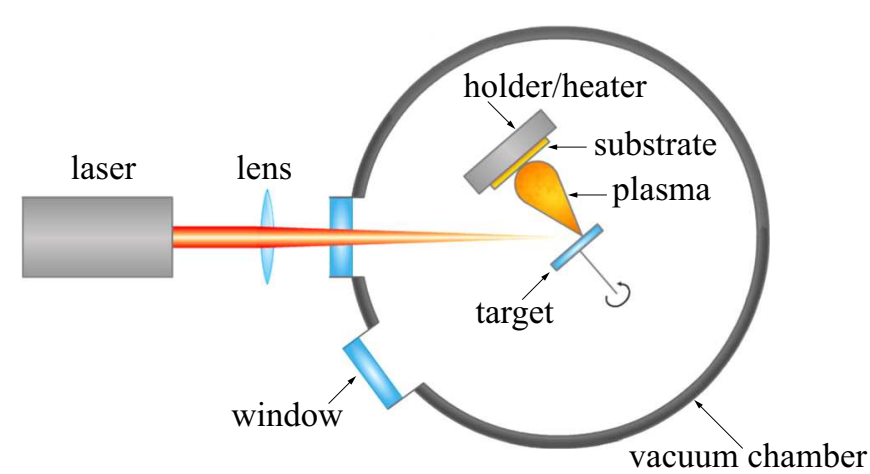

Рис. 1. Схема импульсного лазерного осаждения.
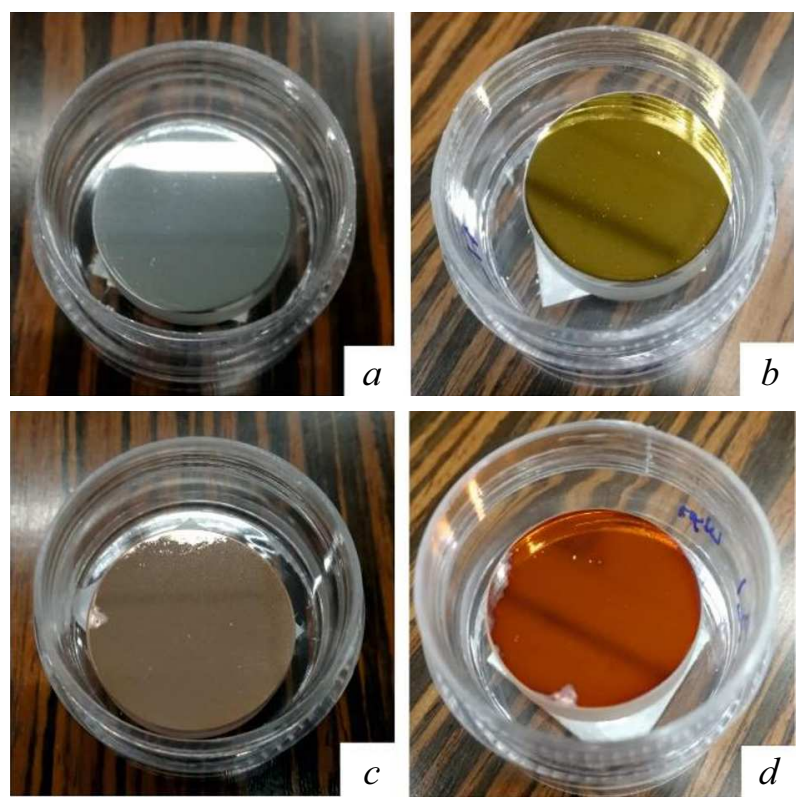

Рис. 2. Изображения зеркал: $a-\mathrm{Al}$ до упрочнения, $b-$ $\mathrm{Al}$ после упрочнения, $c-\mathrm{Cu}$ до упрочнения, $d-\mathrm{Cu}$ после упрочнения.

которой проводят обработку измерений эллипсометра IR-VASE. Толщина DLC-покрытия, нанесенного на алюминиевое зеркало, оказалась равной $29.9 \mathrm{~nm}$, на медное - $30.4 \mathrm{~nm}$.

На рис. 2 представлены фотографии зеркал первой и второй серии до и после нанесения алмазоподобного покрытия.

Для анализа эффективности применения предлагаемого подхода до и после нанесения алмазоподобного покрытия были измерены твердость, форма, шероховатость и коэффициент отражения поверхности.

\section{Определение прочностных характеристик покрытий}

Определение твердости алмазоподобных покрытий проводилось методом наноиндентирования, который 
Таблица 1. Параметры технологического процесса осаждения $D L C$-покрытий

\begin{tabular}{c|c|c|c|c|c}
\hline $\begin{array}{c}\text { Материал } \\
\text { зеркала }\end{array}$ & $\begin{array}{c}\text { Количество } \\
\text { импульсов }\end{array}$ & $\begin{array}{c}\text { Энергия } \\
\text { импульса, } \\
\text { mJ }\end{array}$ & $\begin{array}{c}\text { Давление } \\
\text { в камере, } \\
\text { Torr }\end{array}$ & $\begin{array}{c}\text { Расстояние между } \\
\text { подложкой и } \\
\text { мишенью, mm }\end{array}$ & $\begin{array}{c}\text { Частота } \\
\text { импульсов, } \\
\text { Нz }\end{array}$ \\
\hline $\mathrm{Al}$ & 4000 & 140 & $1 \cdot 10^{-7}$ & 70 & 15 \\
\hline $\mathrm{Cu}$ & 3000 & 139 & $1 \cdot 10^{-7}$ & 70 & 15
\end{tabular}

Таблица 2. Твердость зеркал

\begin{tabular}{c|c|c|c|c}
\hline & $\begin{array}{c}\text { Al до } \\
\text { упрочнения }\end{array}$ & $\begin{array}{c}\text { Al после } \\
\text { упрочнения }\end{array}$ & $\begin{array}{c}\text { Сu до } \\
\text { упрочнения }\end{array}$ & $\begin{array}{c}\text { Сu после } \\
\text { упрочнения }\end{array}$ \\
\hline Твердость, GPa & 2.05 & 2.55 & 2.45 & 5.34
\end{tabular}

заключается во внедрении геометрически и физически аттестованной пирамиды (пирамида Берковича с углом при вершине $65.3^{\circ}$ и радиусом закругления $200 \mathrm{~nm}$ ) в материал покрытия и определении зависимости нагрузки от глубины индентирования [12].

Для определения механических свойств исследуемых образцов методом наноиндентирования был использован измерительный комплекс TI 750L Ubi, который имеет разрешение по деформации $0.0004 \mathrm{~nm}$ и позволяет определять на образцах и покрытиях толщиной от $20 \mathrm{~nm}$ следующие характеристики: твердость и модуль Юнга в зависимости от деформации, адгезию тонких пленок, скретч-тест и износостойкость поверхности. Диапазон нагрузок данной системы составляет $30 \mathrm{nN}-10 \mathrm{~N}$. Исследования проводились при температуре воздуха $25^{\circ} \mathrm{C}$ и относительной влажности воздуxa $16 \%$.

Испытания проводились по модели измерений Оливера-Фарра (ISO-14577, ГОСТ Р 8.748-2011) с глубиной погружения в диапазоне $10-50 \%$ предполагаемой толщины покрытия. Для того чтобы определить свойства покрытия и минимизировать влияние подложки на результат измерения, внедрение наноиндентора выполнялось на глубину, не превышающую $50 \%$ от толщины покрытия. Для проведения серии испытаний проводилось предварительное определение рельефа поверхности площадью $35 \times 35 \mu \mathrm{m}^{2}$ методом атомной силовой микроскопии. Индентирование производилось по шаблонной матрице $5 \times 5$ (всего 25 вдавливаний), с расстоянием между соседними узлами по осям $5 \mu \mathrm{m}$.

В табл. 2 приведены значения твердости образцов, полученные в результате статистической обработки результатов измерений. Видно, что твердость образцов алюминиевых зеркал в результате нанесения упрочняющего алмазоподобного покрытия возрастает на 25\%, а медных зеркал - более, чем в 2 раза.

\section{Определение оптических характеристик $D L C$-покрытия после нанесения}

Определение коэффициента отражения исследуемых образцов проводилось на спектрофотометре PerkinElmer Lambda 950. Спектры отражения исследуемых образцов были получены с использованием универсальной приставки зеркального отражения в диапазоне длин волн от 400 до $1000 \mathrm{~nm}$ с разрешением $0.05 \mathrm{~nm}$ при углах падения света на образец $8^{\circ}$ и $45^{\circ}$. Спектры отражения исследуемых образцов при угле падения света на образец $8^{\circ}$ показаны на рис. 3. Спектры отражения при угле падения света на образец $45^{\circ}$ выглядят аналогичным образом.

Таким образом, нанесение упрочняющих алмазоподобных покрытий методом импульсного лазерного осаждения лишь незначительно снижает коэффициент отражения алюминиевых и медных зеркал, в диапазоне длин волн от 800 до $1000 \mathrm{~nm}$ ухудшение составляет $\sim 5 \%$.

\section{Определение параметров отклонения формы}

Одной из важнейших характеристик оптической поверхности является погрешность ее формы, которая может проявиться в виде общей погрешности формы, локальных погрешностей, а также в шероховатости поверхности. Требования к допустимым значениям этих величин зависят от области применения оптической детали. Типовыми можно считать следующие величины: максимальное значение общей и локальных погрешностей не должны превышать 1/20 длины волны, шероховатость не более $0.05 \mu \mathrm{m}$. Кроме того, для оптических поверхностей вводятся классы чистоты, которые показывают количество и размеры дефектов поверхности (царапин, точек).

Погрешности формы измеряют в первую очередь интерферометрическими методами; шероховатость - 
Таблица 3. Параметры формы зеркал

\begin{tabular}{c|c|c|c|c}
\hline & $\begin{array}{c}\text { Аl до } \\
\text { упрочнения }\end{array}$ & $\begin{array}{c}\text { Al после } \\
\text { упрочнения }\end{array}$ & $\begin{array}{c}\text { Сu до } \\
\text { упрочнения }\end{array}$ & $\begin{array}{c}\text { Cu после } \\
\text { упрочнения }\end{array}$ \\
\hline СКО формы, $\mathrm{nm}$ & 21.3 & 22.5 & 20.1 & 21.5
\end{tabular}

Таблица 4. Параметры шероховатости зеркал

\begin{tabular}{c|c|c|c|c}
\hline & $\begin{array}{c}\text { Al до } \\
\text { упрочнения }\end{array}$ & $\begin{array}{c}\text { Al после } \\
\text { упрочнения }\end{array}$ & $\begin{array}{c}\text { Сu до } \\
\text { упрочнения }\end{array}$ & $\begin{array}{c}\mathrm{Cu} \text { после } \\
\text { упрочнения }\end{array}$ \\
\hline$R a, \mathrm{~nm}$ & 1.30963 & 1.41649 & 1.31407 & 2.18299
\end{tabular}
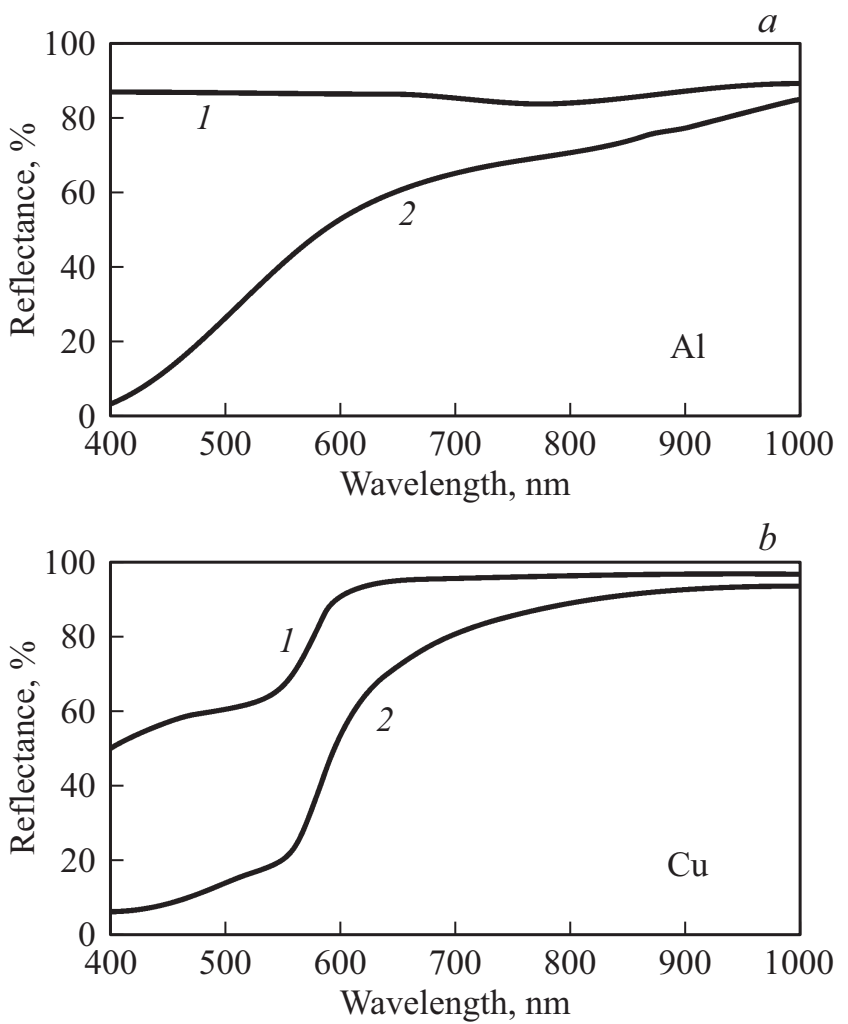

Рис. 3. Спектры отражения исследуемых образцов зеркал с алюминиевым $(a)$ и медным покрытием $(b)$ : кривая 1 - до упрочнения; кривая 2 - после упрочнения.

с помощью микропрофилометра. Выполненные в работе исследования показали, что влияние наносимых упрочняющих параметров на параметры отклонения формы не существенное. Измерение погрешности формы выполнено на интерферометре Физо Zygo GPI ХР. Интерференционные картины зеркал представлены на рис. 4. В табл. 3 приведены численные значения параметров отклонения формы. Среднеквадратические отклонения (СКО) формы зеркал вычислены в результате статистической обработки по 5 интерференционным картинам.

\section{Определение параметров отклонения шероховатости}

Шероховатость поверхности образцов до и после нанесения углеродного алмазоподобного покрытия была определена методом атомно-силовой микроскопии на установке Ntegra Spectra. Исследования образцов осуществлялись в полуконтактном режиме на воздухе при температуре окружающей среды $22^{\circ} \mathrm{C}$ и влажности $25 \%$ в чистой комнате (класс чистоты 7 по стандарту DIN EN ISO14644 ч. I) методом постоянной амплитуды. Для регистрации участков зеркал размером $50 \times 50 \mu \mathrm{m}^{2}$ с разрешением $512 \times 512$ точек применялись высокоразрешающие кремниевые кантилеверы.

На рис. 5 показаны изображения микроструктуры зеркал, полученные с помощью сканирующего зондового микроскопа до и после упрочнения. В табл. 4 приведены
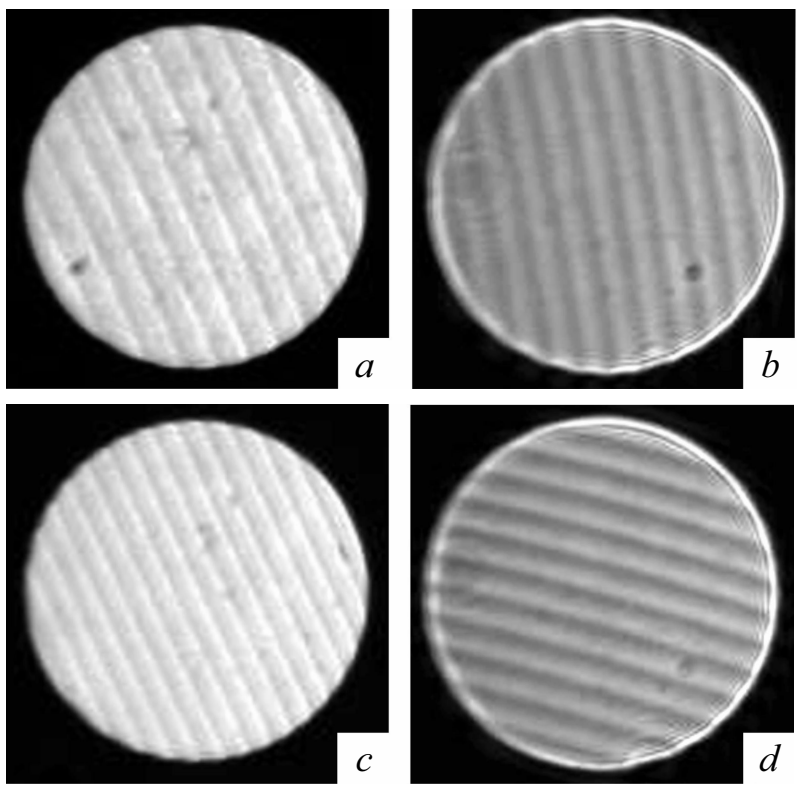

Рис. 4. Интерференционные картины зеркал: $a-\mathrm{Al}$-зеркало до упрочнения; $b-\mathrm{Al}$-зеркало после упрочнения; $c-\mathrm{Cu}-$-зеркало до упрочнения; $d-\mathrm{Cu}$-зеркало после упрочнения. 

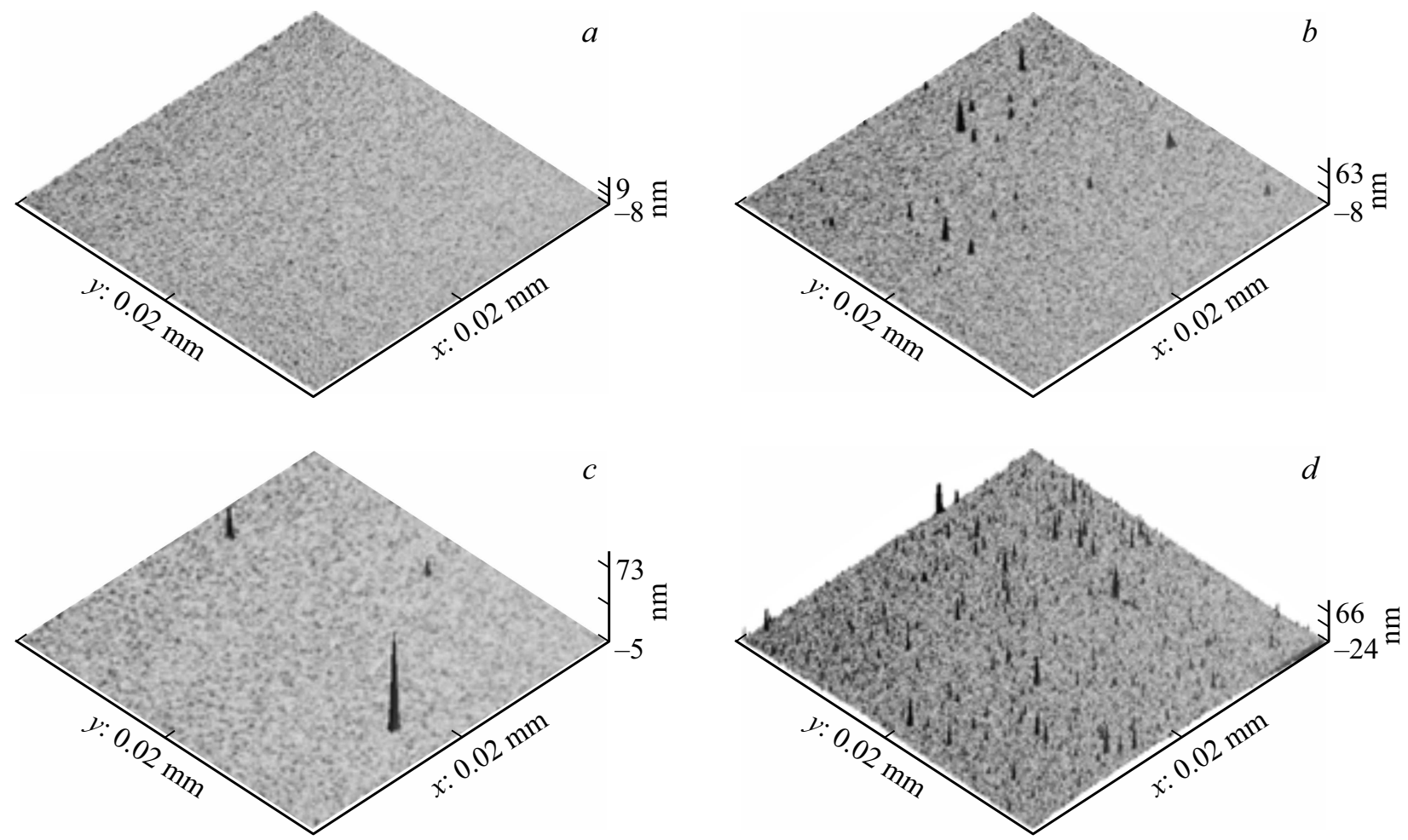

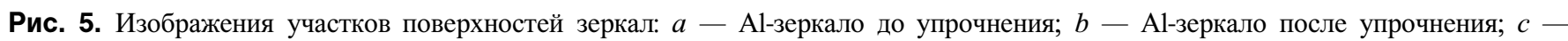
$\mathrm{Cu}$-зеркало до упрочнения; $d-\mathrm{Cu}$-зеркало после упрочнения.

численные значения параметров отклонения шероховатости.

\section{Заключение}

Анализ полученных результатов, представленных в табл. 2-4 и на рис. 3-5, показывает следующее. Нанесение $D L C$-покрытия толщиной $30 \mathrm{~nm}$ методом импульсного лазерного осаждения на алюминиевые и медные зеркала на стеклянных подложках позволило повысить твердость их отражающих поверхностей. При этом не происходит искажение исходной формы зеркала и увеличение его шероховатости, однако наблюдается существенное снижение коэффициента отражения в видимом диапазоне $(400-780 \mathrm{~nm})$, тогда как в инфракрасном $(>780 \mathrm{~nm})$ оно не превосходит 5\%. Поэтому наиболее перспективным представляется применение данной технологии упрочнения для зеркал, входящих в состав космической аппаратуры, предназначенной для работы в инфракрасной области спектра.

\section{Конфликт интересов}

Авторы заявляют, что у них нет конфликта интересов.

\section{Список литературы}

[1] Lawrence A. Astronomical Measurements. Springer-Verlag Berlin Heidelberg. 2014. 192 p.

[2] Trumper I. et al. // Adv. Opt. Photon. 2018. V. 10. P. 644-702. doi 10.1364/AOP.10.000644

[3] Кардашев Н.С. и др. // Тр. Физич. ин-та им. П.Н. Лебедева. 2000. T. 228. C. 112.

[4] Bewilogua K., Hofmann D. // Surf. Coat. Technol. 2014. V. 242. P. 214-225.

[5] Macleod H. Thin-Film Optical Filters, 4th ed. CRC Press, Boca Raton, Florida, 2010. 782 p.

[6] Klyui N.I., Litovchenko V.G., Lukyanov A.N., Neselevska L.V., Osovskiy V.D., Yaroschuk O.V., Dolgov L.A. // Ukr. Phys. J. 2006. V. 51. N 7. P. 710-714.

[7] Сизов Ф.Ф., Клюй Н.И., Лукьянов А.Н., Савкина Р.К., Смирнов А.Б., Евменова А.З. // Письма в ЖТФ. 2008. Т. 34. B. 9 . C. $32-40$.

[8] Robertson J. // Materials Science and Engineering. 2002. P. 129-281.

[9] НОЦ „Функциональные микро/нано системы“ [Электронный ресурс] Режим доступа:

http://fmn.bmstu.ru/technology/equipment/metrology/nanofab/

[10] Дубровский B. Теория формирования эпитаксиальных наноструктур М.: Физматлит, 2009. 352 с.

[11] IR-VASE User's Manual // J.A. Woollam Co.Inc., 2006.

[12] Makeev M.O., Ivanov Yu.A., Meshkov S.A., Gil'man A.B., Yablokov M.Yu. // High Energy Chem. 2011. V. 45. P. 536-538. doi 10.1134/S0018143911060129 